\title{
40 MAKING PERSON CENTRED CARE A REALITY
}

10.1136/bmjspcare-2011-000053.40

L Wigley', G Bailey² 'Humber and Yorkshire Coast Cancer Network, East Yorkshire, UK; ${ }^{2}$ Helen Sanderson Associates, UK

This workshop will showcase innovative work that was led by Helen Sanderson Associates, which culminated in developing 'Living Well: Thinking and Planning for the End of Your Life'. This work brought together Hull City Council Adult Social Care, Humber and Yorkshire Coast Cancer Network, City Healthcare Partnership, Macmillan, Hull Churches Home from Hospital, Dove House Hospice, patients and carers to consider how person centred thinking tools could be used within a patients journey to increase the quality of their experience of palliative and end of life care.

One example of its practical implementation is Edna. Edna is an older person who has dementia. By training and supporting staff in using the tools in their conversations with Edna and her family, staff have gained a better insight into who she is as an individual, her preferences, beliefs and care needs. We have mapped Edna's clinical journey and identified where these tools will provide information to inform health and social care professionals to understand what is important to Edna and what best support looks like.

This work is an innovative mechanism for working across health, social care and the third sector. The work adds to what is already known, by providing a method for gathering person centred information that can be used in Advance Care Planning to ensure the care provided is the best possible quality for that individual and their carer. Overall, this workshop will provide a clear example of how person-centred care can be achieved in current service provision. 